\title{
Preoperative pulmonary function testing and postoperative complications
}

\author{
Yusuke Takahashi ${ }^{1,2}$, Shigeki Suzuki ${ }^{1}$ \\ ${ }^{1}$ Department of General Thoracic Surgery, Sagamihara Kyodo Hospital, Sagamihara, Kanagawa, Japan; ${ }^{2}$ Department of General Thoracic Surgery, \\ Teikyo University School of Medicine, Itabashi, Tokyo, Japan \\ Correspondence to: Yusuke Takahashi, MD, PhD. Department of General Thoracic Surgery, Sagamihara Kyodo Hospital, 2-8-18 Hashimoto, Midori- \\ ku, Sagamihara, Kanagawa 252-5188, Japan. Email: yusuketakahashigts@gmail.com. \\ Provenance: This is an invited Editorial commissioned by Executive Editor-in-Chief Jianxing He (Director of the Thoracic Surgery Department, The \\ First Affiliated Hospital of Guangzhou Medical University, Guangzhou, China). \\ Comment on: Hudson JL, Bell JM, Crabtree TD, et al. Office-Based Spirometry: A New Model of Care in Preoperative Assessment for Low-Risk \\ Lung Resections. Ann Thorac Surg 2018;105:279-86.
}

Submitted Aug 26, 2018. Accepted for publication Sep 11, 2018.

doi: $10.21037 /$ jtd.2018.09.37

View this article at: http://dx.doi.org/10.21037/jtd.2018.09.37

Lung resection is the standard therapeutic option for early-stage non-small cell lung cancer and its incidence has been increasing worldwide (1). Postoperative pulmonary complications are associated with increased postoperative mortality and prolonged hospital stay (2-4). Thus, many investigators have reported risk factors of postoperative pulmonary complications $(5,6)$. Particularly, it must be clinically useful to stratify risk of postoperative complications with simple and non-invasive assessment methods including computed tomography (CT) findings $(7,8)$ and exercise testing (9-11). On the other hand, conventional laboratory spirometry (LS) is the gold standard in preoperative assessment for risk stratification of postoperative pulmonary complications to date (12-14) and the quality of life following pulmonary resection is strongly associated with long-term change of LS parameters $(15,16)$ which is significantly influenced by degree of compensatory response (17) as well as preoperative smoking status (18). However, in some situations, limited medical resources cannot necessarily allow us to perform LS.

For these reasons, some researchers have investigated potential clinical relevance of office-based spirometry (OS) that can be easily performed in outpatient office with less cost and time (19). Previous investigations demonstrated that OS parameters including expiratory volume in one second (FEV1) and forced vital capacity (FVC) had been significantly correlated with LS parameters (20) and OS was reportedly useful for screening of chronic obstructive pulmonary disease (COPD) (21). In a recent paper of Hudson et al. in the Annals of Thoracic Surgery (22), the authors demonstrated that patients who had undergone preoperative OS had experienced similar major morbidity to those who had undergone preoperative LS after propensity score matching. Their data suggests that OS can be used as preoperative assessment without LS. This finding could be a basis for planning a prospective study to compare predictive ability of postoperative pulmonary complications between OS and LS. Meanwhile, they enrolled only low-risk patients in this study, which may result in no postoperative mortality and quite low readmission rate.

For thoracic surgeons, stratifying poor risk patients is one of the most important clinical demands. It may lead us to select less-invasive treatment including sublobar resection or stereotactic body radiotherapy. Whereas, it is still unknown whether OS can be used in normal or highrisk patients as preoperative assessment, because Hudson et al. employed only low-risk patients (22). Of note, almost two third patients had undergone sublobar resection even after propensity matching. It may cause very few events, so that potentially LS as well as OS could be omitted preoperatively.

In considering future routine use of preoperative OS, it is mandatory to investigate whether OS has similar predictive ability of postoperative morbidity especially in normal and 
high-risk patients. Although the previous study had shown significant correlation between OS and LS for both forced FEV1 and FVC in patients with COPD (20), it should be also noted that there are patients at high-risk for pulmonary complications even if the spirometry data does not show low FEV1/FVC $(8,23)$. Moreover, it is also great interests of pulmonary physicians whether both FEV1 and FVC of OS show significant association with those of LS in patients with a variety of pathologies.

OS is easily available and notably economical test compared with LS (24). These robust benefits are clinically significant in any setting. Since preoperative evaluation is often time-consuming and futile, it is sometimes stressful for patients as well as physicians.

In summary, the novel simple and cost-effective spirometry and its usefulness in preoperative evaluation in normal and high-risk patients needs to be investigated in large-scale cohort, possibly in prospective study. Better risk stratification of postoperative complication with using OS may improve our clinical practice and impact on medical economy in near future.

\section{Acknowledgements}

We thank Marissa Mayor of Washington University Surgery Service for her editorial assistance.

\section{Footnote}

Conflicts of Interest: The authors have no conflicts of interest to declare.

\section{References}

1. Jemal A, Bray F, Center MM, et al. Global cancer statistics. CA Cancer J Clin 2011;61:69-90.

2. Shi Y, Yu H, Huang L, et al. Postoperative pulmonary complications and hospital stay after lung resection surgery: A meta-analysis comparing nonintubated and intubated anesthesia. Medicine (Baltimore) 2018;97:e10596.

3. Wang $\mathrm{S}, \mathrm{Li} \mathrm{X}, \mathrm{Li} \mathrm{Y}$, et al. The long-term impact of postoperative pulmonary complications after video-assisted thoracic surgery lobectomy for lung cancer. J Thorac Dis 2017;9:5143-52.

4. Dong J, Mao Y, Li J, et al. Stair-Climbing Test Predicts Postoperative Cardiopulmonary Complications and Hospital Stay in Patients with Non-Small Cell Lung
Cancer. Med Sci Monit 2017;23:1436-41.

5. Taylor LJ, Julliard WA, Maloney JD. Predictive value of pulmonary function measures for short-term outcomes following lung resection: analysis of a single high-volume institution. J Thorac Dis 2018;10:1072-6.

6. Pforr A, Pagès PB, Baste JM, et al. A Predictive Score for Bronchopleural Fistula Established Using the French Database Epithor. Ann Thorac Surg 2016;101:287-93.

7. Li SJ, Zhou K, Wu YM, et al. Presence of pleural adhesions can predict conversion to thoracotomy and postoperative surgical complications in patients undergoing video-assisted thoracoscopic lung cancer lobectomy. J Thorac Dis 2018;10:416-31.

8. Takahashi Y, Matsuda M, Aoki S, et al. Qualitative Analysis of Preoperative High-Resolution Computed Tomography: Risk Factors for Pulmonary Complications After Major Lung Resection. Ann Thorac Surg 2016;101:1068-74.

9. Fennelly J, Potter L, Pompili C, et al. Performance in the shuttle walk test is associated with cardiopulmonary complications after lung resections. J Thorac Dis 2017;9:789-95.

10. Brunelli A, Pompili C, Berardi R, et al. Performance at preoperative stair-climbing test is associated with prognosis after pulmonary resection in stage I non-small cell lung cancer. Ann Thorac Surg 2012;93:1796-800.

11. Benzo RP, Sciurba FC. Oxygen consumption, shuttle walking test and the evaluation of lung resection. Respiration 2010;80:19-23.

12. Benattia A, Debeaumont D, Guyader V, et al. Physiologic assessment before video thoracoscopic resection for lung cancer in patients with abnormal pulmonary function. J Thorac Dis 2016;8:1170-8.

13. Ferguson MK, Watson S, Johnson E, et al. Predicted postoperative lung function is associated with all-cause long-term mortality after major lung resection for cancer. Eur J Cardiothorac Surg 2014;45:660-4.

14. Brunelli A, Kim AW, Berger KI, et al. Physiologic evaluation of the patient with lung cancer being considered for resectional surgery: Diagnosis and management of lung cancer, 3rd ed: American College of Chest Physicians evidence-based clinical practice guidelines. Chest 2013;143:e166S-90S.

15. Liu W, Pan YL, Gao CX, et al. Breathing exercises improve post-operative pulmonary function and quality of life in patients with lung cancer: A meta-analysis. Exp Ther Med 2013;5:1194-200.

16. Greillier L, Thomas P, Loundou A, et al. Pulmonary function tests as a predictor of quantitative and qualitative 
outcomesafter thoracic surgery for lung cancer. Clin Lung Cancer 2007;8:554-61.

17. Ueda K, Tanaka T, Hayashi M, et al. Compensation of pulmonary function after upper lobectomy versus lower lobectomy. J Thorac Cardiovasc Surg 2011;142:762-7.

18. Takahashi Y, Matsutani N, Morita S, et al. Predictors of long-term compensatory response of pulmonary function following major lung resection for non-small cell lung cancer. Respirology 2017;22:364-71.

19. Enright Md P. Office-based DLCO tests help pulmonologists to make important clinical decisions. Respir Investig 2016;54:305-11.

20. Bambra G, Jalota L, Kapoor C, et al. Office spirometry correlates with laboratory spirometry in patients with symptomatic asthma and COPD. Clin Respir J 2017;11:805-11.

Cite this article as: Takahashi Y, Suzuki S. Preoperative pulmonary function testing and postoperative complications. J Thorac Dis 2018;10(Suppl 33):S3840-S3842. doi: 10.21037/ jtd.2018.09.37
21. Yawn BP, Duvall K, Peabody J, et al. The impact of screening tools on diagnosis of chronic obstructive pulmonary disease in primary care. Am J Prev Med 2014;47:563-75.

22. Hudson JL, Bell JM, Crabtree TD, et al. Office-Based Spirometry: A New Model of Care in Preoperative Assessment for Low-Risk Lung Resections. Ann Thorac Surg 2018;105:279-86.

23. Ferguson MK, Vigneswaran WT. Diffusing capacity predicts morbidity after lung resection in patients without obstructive lung disease. Ann Thorac Surg 2008;85:1158-64.

24. Schoh RJ, Fero LJ, Shapiro H, et al. Performance of a new screening spirometer at a community health fair. Respir Care 2002;47:1150-7. 